\title{
Prevalence of Attention-Deficit/Hyperactivity Disorder (ADHD) Among Pre-School Children in Al-Qalyubiya Governorate
}

H.A.El Ghaiaty, T.M.Khatab, A.A.Sobeih and M.F.Abdel rahman

Pediatrics, Dept., Faculty of Medicine, Benha Univ., Benha, Egypt

E-mail:hamadah.ali@gmail.com

\begin{abstract}
Background; neuro-behavioral illness is the most common in both children and adolescents. It is characterised by carelessness and hyperactivity, which often cause behavioural and academic difficulties. It affects 3-12\% of newborns with a male/female ratio of 3:1 to 9:1. Objectives and objectives; to evaluate the prevalence of ADHD in pre-school Governorate Al-Qalyubiya children; Themes and technology; This is a transversal study conducted in the governorate of Al-Qalyubiya with 1345 pre-school children. Field work was carried out throughout the first half of 2020, Results; ADHD subtypes and sex have had a significantly higher connection than ADHD-C and ADHD$\mathrm{HI}$ in children than girls and ADHD-I subtypes in women compared to boys; Conclusion; ADHD is a major problem that young people between the ages of 3 and 6 frequently suffer from. Early detection and parenting programmes should be developed to enhance parental skills in the control of their child's behaviour.
\end{abstract}

Keywords: Attention-deficit/hyperactivity disorder (ADHD), Epidemiology, Preschool children, Prevalence.

\section{Introduction}

ADHD is a neurodevelopmental illness with a specific behavioural pattern that may impair the functioning of people in social, educational and vocational contexts. It affects about $3-12 \%$ of newborns with a ratio of 3:1 to 9:1 between men and women. Approximately 30-50 percent of youngsters still have adult symptoms. The hyperactivity condition may impact all area of the child's function and influence school, family and peer relationships. The result is severe academic delays, a lack of learning and self-esteem, complicating subsequent clinical presentation and treatment [1].

The aetiology of most ADHD cases is unknown, but genetic and environmental factors are believed to be involved. Three different kinds of ADHD are present; mixed ADHD is the most common, including hyperactivity and impulsive symptoms. ADHD is characterised by a lower attention and focus. Unattended hyperactivity characterises hyperactive-pulsive ADHD[2].

Earlier study in Egypt showed that hyperactivity with attention deficit is a significant public health problem for youngsters. ADHD diagnosis is based on the criteria of the Fifth Edition Diagnose and Statistical Manual of Mental Disorders of the American Psychiatric Association (DSM V). ADHD therapy includes counselling, conduct therapy, nutritional therapy or their combination. Regardless of the approach, early and effective treatment of ADHD is indicated to result in better prognoses and a reduction in adult problems[3].

Limited data are available on the prevalence and risk factors of ADHD in pre-school children. The aim of this research is to measure the prevalence of ADHD among pre-school children in AlQalyubiya Governorate.

The aim of this research was to evaluate the incidence of ATDH among pre-school children in Al-Qalyubiya Governorate.

\section{Patients and methods}

This is a sectional cross study, In the first half of the year 2020, the field work was scheduled but was postponed as a result of the COVID-19 epidemic owing to widespread national closures of government and private schools and pre-schools. The fieldwork was then conducted from November 2020 to May 2021 during the school year 2020/2021. The research was performed in the Al-Qalyubiya Governorate on pre-school children in governmental and private pre-schools.

The participants were recruited using the Multistage method of sampling via a division between the governorate of Al-Qalyubiya and clusters in 10 districts (Banha - Chanka - Qaha - Qalyub - Shibin Al-Qanater - Shubra El-Kheima - Tukh - Al Kanater Al Khhairia - Kafr Shukra - Al-Khosoas). Six of the districts were selected on a random simple sample (Banha - Qalyub - Shibin Al-Kanater Shubra El-Kheima - Tukh - Kafr Shukr) Eight preschools from each district were included, four rural and four city by simple random sampling.

In private and government schools the necessary sample was supported by all pupils available; since the number of school attendants dropped significantly as a result of the COVID-19 epidemic.

It had 1345 children (610 males and 735 girls). A teacher questionnaire was completed for each kid by the appropriate teacher. In addition, a risk factors questionnaire was given to parents in their child's luggage. All the surveys of the teacher were completed (1345 questionnaires), but only (824 questionnaires) the questionnaires of the risk factors were fully completed and returned by the parents.

\subsection{Inclusion criteria}

- Both genders.

- Age between 2-6 years. 


\subsection{Exclusion criteria}

- Neurological handicapping.

An approval from the Research Ethics Committee in Benha faculty of medicine was obtained. Approvals were obtained from the Central Agency for Public Mobilization and Statistics and from the Educational Administration of AlQalyubiya Governorate, Approvals were obtained from children caregivers after complete explanation of the aim and methodology of the study and that their participation was voluntary and all data included in the study is confidential and would not be shared with a third party and would only be used for research purpose .Teachers were asked to fill the Arabic forms of Conner's teacher scale for each child.

\subsection{Statistical analysis}

Data was collected, coded then entered as a spread sheet using Microsoft Excel 2016 for Windows, of the Microsoft Office bundle; 2016 of Microsoft Corporation, United States. Data was analyzed using IBM Statistical Package for Social Sciences software (SPSS), (IBM SPSS Statistics for Windows, and Version 26.0. Armonk, NY: IBM Corp). The Kolmogorov-Smirnov test was used to verify the normality of distribution. Continuous data was expressed as mean \pm standard deviation, median \& IQR while categorical data as numbers and percentage. A statistical value $<0.05$ was considered as significant.

\section{Results}

This cross sectional studystudy was conducted on 1345 pre-school children in AlQalyubiya Governorate.

Table (1) illustrates distribution of sociodemographic characteristics of studied subjects. The age of studied children was ranged from 2.11 to 5.9 years with mean \pm SD was $4.96 \pm 0.77$ years and median of 4.9 years. The commonest age involved was (pre-school age) $4.0-<6.0$ years age group $(84.5 \%) .610(45.5 \%)$ of children were boys and 735 $(54.6 \%)$ were girls with boys to girls ratio of $0.83: 1$. $646(48 \%)$ children were on KG2. 739 (45.9\%) of cases were from urban areas. The majority of children were going governmental school.

Table (2) shows that the prevalence of ADHD in our study was $6.3 \% .45(3.3 \%)$ of them had ADHDCombined subtype, $26(1.9 \%)$ had ADHDHyperactive/Impulsive, and 14 (1.0\%) had ADHDInattentive subtype. On the other hand, it was found that $45(3.3 \%)$ had Conduct problem.

Table (1) Distribution of socio-demographic characteristics of studied subjects

\begin{tabular}{|c|c|c|c|}
\hline \multirow[t]{2}{*}{ Parameters } & & \multicolumn{2}{|c|}{$\begin{array}{c}\text { Studied children } \\
\quad(n=1345)\end{array}$} \\
\hline & & $\mathbf{n}$ & $\%$ \\
\hline \multirow{4}{*}{ Age (years) } & Mean \pm SD & \multicolumn{2}{|c|}{$4.96 \pm 0.77$} \\
\hline & Median & \multicolumn{2}{|c|}{4.90} \\
\hline & Minimum & \multicolumn{2}{|c|}{2.11} \\
\hline & Maximum & & \\
\hline \multirow{2}{*}{ Age distribution } & 1-3 years (Toddler) & 208 & $15.5 \%$ \\
\hline & 4- 5 years (Pre-School) & 1137 & $84.5 \%$ \\
\hline \multirow{3}{*}{ Gender } & Boys & 610 & $45.4 \%$ \\
\hline & Girls & 735 & $54.6 \%$ \\
\hline & Nursery & 208 & $15.5 \%$ \\
\hline \multirow[t]{2}{*}{ Grade } & KG1 & 491 & $36.5 \%$ \\
\hline & KG2 & 646 & $48.0 \%$ \\
\hline \multirow{2}{*}{ Residence } & Rural & 606 & $45.1 \%$ \\
\hline & Urban & 739 & $54.9 \%$ \\
\hline \multirow{2}{*}{ Type of preschool } & Governmental & 880 & $65.4 \%$ \\
\hline & Private & 465 & $34.6 \%$ \\
\hline
\end{tabular}

$\mathrm{SD}=$ standard deviation, $\mathrm{n}$ : number, $\%$ : percentage,

Table (2) Classification of the studied group according to probable presence of ADHD, ADHD subtypes and probable presence of Conduct problem

\begin{tabular}{llcc}
\hline \multirow{2}{*}{ Parameters } & & \multicolumn{2}{c}{ Studied subjects (n= 1345) } \\
\hline ADHD classification & Positive & 85 & $6.3 \%$ \\
& Negative & 1260 & $93.7 \%$ \\
ADHD Subtype & Combined (ADHD-C) & 45 & $3.3 \%$ \\
& Hyperactive/Impulsive & 26 & $1.9 \%$ \\
\hline
\end{tabular}




\begin{tabular}{llcc}
\hline & Inattentive (ADHD-HI) & 14 & $1.0 \%$ \\
Conduct Problem & Positive & 45 & $3.3 \%$ \\
& Negative & 1300 & $96.7 \%$ \\
\hline
\end{tabular}

$\mathrm{SD}=$ standard deviation, $\mathrm{n}$ : number, \%: percentage,

Another questionnaire was performed for parents. There were 824 responders for this questionnaire. Table (3) shows socio-demographic characteristics of children's family. 27 (3.3\%) children had family history of ADHD. Of the children, $396(48.1 \%)$ were the second child in birth order. Regarding father education, 456 (55.3\%) of father had secondary education. Majority of father (91.3\%) were employed. Regarding mother education, $484(58.7 \%)$ of mothers had secondary education. Majority of mothers (78.2\%) were unemployed. Regarding socioeconomic level, $64.3 \%$ of families had middle level. 220 (26.7\%) parents had positive consanguinity. Most children (79\%) were living with both parents. Concerning punishment, the parents punished their children by hitting in $60(7.3 \%)$ cases, bad words in $66(8 \%)$ and by insulting in $47(57 \%)$ cases. Parents relationship was good in $633(76.8 \%)$ families and parent-child relationship were good in 692 (84\%) families.

Table (4) shows clinical data of children and their mothers. During pregnancy, 30 (3.6\%) mothers had hypertension, 65 (7.9\%) used drugs. 9 (1.1\%) mothers were smoking during pregnancy and 102 $(12.4 \%)$ mothers exposed to passive smoking. Regarding mode of delivery, $533(64.7 \%)$ mothers delivered by normal vaginal delivery. Low birth weight was observed in $68(8.3 \%)$ cases and prematurity was found in $52(6.3 \%)$ cases. Cyanosis was found in $34(4.1 \%)$ cases. The mean age of mother at time of delivery was $25.10 \pm 2.97$. Regarding feeding, most children $(64.8 \%)$ fed by breast feeding. $384(46.6 \%)$ children were watching TV. 248 (30.1\%) children had head trauma.

Table (3) Distribution of socio-demographic characteristics of children's family

\begin{tabular}{|c|c|c|c|}
\hline \multirow[t]{2}{*}{ Parameters } & & \multicolumn{2}{|c|}{$\begin{array}{l}\text { Studied subjects } \\
\quad(n=824)\end{array}$} \\
\hline & & n & $\%$ \\
\hline \multirow{2}{*}{ Family history of ADHD } & Yes & 27 & $3.3 \%$ \\
\hline & No & 797 & $96.7 \%$ \\
\hline \multirow{5}{*}{ Birth Order } & $\mathbf{1}^{\text {st }}$ child & 255 & $30.9 \%$ \\
\hline & $2^{\text {nd }}$ child & 396 & $48.1 \%$ \\
\hline & $3^{\text {rd }}$ child & 148 & $18.0 \%$ \\
\hline & $>3^{\text {rd }}$ child & 25 & $3.0 \%$ \\
\hline & Illiterate & 36 & $4.4 \%$ \\
\hline \multirow{3}{*}{ Father education } & Primary & 61 & $7.4 \%$ \\
\hline & Secondary & 456 & $55.3 \%$ \\
\hline & Above secondary & 271 & $32.9 \%$ \\
\hline \multirow{3}{*}{ Father occupation } & Employed & 752 & $91.3 \%$ \\
\hline & Unemployed & 72 & $8.7 \%$ \\
\hline & Illiterate & 53 & $6.4 \%$ \\
\hline \multirow{3}{*}{ Mother education } & Primary & 68 & $8.3 \%$ \\
\hline & Secondary & 484 & $58.7 \%$ \\
\hline & Above secondary & 219 & $26.6 \%$ \\
\hline \multirow{3}{*}{ Mother occupation } & Employed & 180 & $21.8 \%$ \\
\hline & Unemployed & 644 & $78.2 \%$ \\
\hline & Low & 164 & $19.9 \%$ \\
\hline \multirow[t]{2}{*}{ Socioeconomic level } & Middle & 530 & $64.3 \%$ \\
\hline & High & 130 & $15.8 \%$ \\
\hline \multirow{3}{*}{ Consanguinity } & Yes & 220 & $26.7 \%$ \\
\hline & No & 604 & $73.3 \%$ \\
\hline & Both parents & 651 & $79.0 \%$ \\
\hline \multirow[t]{3}{*}{ Child lives } & Father only & 45 & $5.5 \%$ \\
\hline & Mother only & 128 & $15.5 \%$ \\
\hline & No & 651 & $79.0 \%$ \\
\hline \multirow{4}{*}{ Punishment } & Hitting & 60 & $7.3 \%$ \\
\hline & Bad words & 66 & $8.0 \%$ \\
\hline & Insulting & 47 & $5.7 \%$ \\
\hline & Good & 633 & $76.8 \%$ \\
\hline \multirow[t]{2}{*}{ Parents relationship } & Irritable & 145 & $17.6 \%$ \\
\hline & Don't know & 46 & $5.6 \%$ \\
\hline
\end{tabular}




\begin{tabular}{llcc}
\hline \multirow{2}{*}{ Parameters } & & \multicolumn{2}{c}{$\begin{array}{c}\text { Studied subjects } \\
(\mathbf{n}=\mathbf{8 2 4})\end{array}$} \\
& & $\mathbf{n}$ & $\mathbf{\%}$ \\
\hline \multirow{2}{*}{ Parent-Child relationship } & Good & 692 & $84.0 \%$ \\
& Irritable & 132 & $16.0 \%$ \\
\hline
\end{tabular}

Table (4) Distribution of clinical data of children and their mothers

\begin{tabular}{|c|c|c|c|}
\hline \multirow[t]{2}{*}{ Parameters } & & \multicolumn{2}{|c|}{$\begin{array}{l}\text { Studied subjects } \\
\quad(n=824)\end{array}$} \\
\hline & & $\mathbf{n}$ & $\%$ \\
\hline \multirow{2}{*}{ HTN of pregnancy } & Yes & 30 & $3.6 \%$ \\
\hline & No & 794 & $96.4 \%$ \\
\hline \multirow{2}{*}{ Drug intake in pregnancy } & Yes & 65 & $7.9 \%$ \\
\hline & No & 759 & $92.1 \%$ \\
\hline \multirow{2}{*}{ Mother smoking in pregnancy } & Yes & 9 & $1.1 \%$ \\
\hline & No & 815 & $98.9 \%$ \\
\hline \multirow{2}{*}{ Passive smoking in pregnancy } & Yes & 102 & $12.4 \%$ \\
\hline & No & 722 & $87.6 \%$ \\
\hline \multirow{4}{*}{ Mother age at time of delivery } & Mean \pm SD & \multicolumn{2}{|c|}{$25.10 \pm 2.97$} \\
\hline & Median & \multicolumn{2}{|c|}{25.0} \\
\hline & Minimum & \multicolumn{2}{|c|}{19.0} \\
\hline & Maximum & \multicolumn{2}{|c|}{36.0} \\
\hline \multirow{2}{*}{ Mode of delivery } & NVD & 533 & $64.7 \%$ \\
\hline & CS & 291 & $35.3 \%$ \\
\hline \multirow{2}{*}{ Birth weight } & Normal & 756 & $91.7 \%$ \\
\hline & LBW & 68 & $8.3 \%$ \\
\hline \multirow{2}{*}{ Prematurity } & Yes & 52 & $6.3 \%$ \\
\hline & No & 772 & $93.7 \%$ \\
\hline \multirow{3}{*}{ Cyanosis } & Yes & 34 & $4.1 \%$ \\
\hline & No & 790 & $95.9 \%$ \\
\hline & Breast milk & 534 & $64.8 \%$ \\
\hline \multirow[t]{2}{*}{ Feeding } & Artificial & 138 & $16.7 \%$ \\
\hline & Both & 152 & $18.4 \%$ \\
\hline \multirow{2}{*}{ Watching TV } & Yes & 384 & $46.6 \%$ \\
\hline & No & 440 & $53.4 \%$ \\
\hline \multirow{2}{*}{ Head trauma } & Yes & 248 & $30.1 \%$ \\
\hline & No & 576 & $69.9 \%$ \\
\hline
\end{tabular}

LBW= Low birth weight, NVD: normal vaginal delivery, CS: Caesarian section

Table (5) Relation between ADHD subtypes and gender

\begin{tabular}{|c|c|c|c|c|c|c|c|}
\hline & & \multicolumn{2}{|c|}{$\begin{array}{c}\text { Boys } \\
(\mathbf{n}=\mathbf{5 3})\end{array}$} & \multicolumn{2}{|c|}{$\begin{array}{c}\text { Girls } \\
(\mathrm{n}=32)\end{array}$} & \multirow[t]{2}{*}{ Test value } & \multirow[t]{2}{*}{ P-value } \\
\hline & & $\mathbf{n}$ & $\%$ & $\mathbf{n}$ & $\%$ & & \\
\hline \multirow{3}{*}{ ADHD subtypes } & ADHD-C & 31 & $5.1 \%$ & 14 & $1.9 \%$ & \multirow{3}{*}{$X^{2}=12.08$} & \multirow{3}{*}{0.002} \\
\hline & ADHD-HI & 19 & $3.1 \%$ & 7 & $1.0 \%$ & & \\
\hline & ADHD-I & 3 & $0.5 \%$ & 11 & $1.5 \%$ & & \\
\hline
\end{tabular}

$\mathrm{p} \leq 0.05$ is considered statistically significant, $\mathrm{p} \leq 0.01$ is considered high statistically significant, -comparison between groups done by Chi- Square test

Table (5) shows that there was significant relation between ADHD subtypes and gender as ADHD- $\mathrm{C}$ and ADHD- HI subtypes was significantly higher in boys compared to girls and ADHD- I subtypes was significantly higher in girls compared to boys.

Table (6) shows factors associated with ADHD among Children. During bivariate analyses of
ADHD, it was revealed that gender, family history of ADHD, socioeconomic level, consanguinity, HTN of pregnancy, drug intake in pregnancy, mother active and passive smoking in pregnancy, mode of delivery, cyanosis and watching TV considered risk factors for development of ADHD ( $p$ value was < 0.05). In addition, Conduct problem is found to be an associated comorbid condition with ADHD. 
Table (6) Factors associated with ADHD among Children.

\begin{tabular}{|c|c|c|c|c|c|c|c|c|c|}
\hline & & \multicolumn{2}{|c|}{ With ADHD } & \multicolumn{2}{|c|}{ Without ADHD } & \multirow[t]{2}{*}{$\mathbf{O R}$} & \multicolumn{2}{|c|}{$\begin{array}{c}95 \% \\
\text { Confidence } \\
\text { Interval }\end{array}$} & \multirow[t]{2}{*}{ P-value } \\
\hline & & $\mathbf{n}$ & $\%$ & $\mathbf{n}$ & $\%$ & & Lower & Upper & \\
\hline \multirow{2}{*}{ Gender } & Boys & 53 & $62.4 \%$ & 557 & $44.2 \%$ & \multirow{2}{*}{2.09} & \multirow{2}{*}{1.329} & \multirow{2}{*}{3.287} & \multirow{2}{*}{0.001} \\
\hline & Girls & 32 & $37.6 \%$ & 703 & $55.8 \%$ & & & & \\
\hline \multirow{2}{*}{ Residence } & Urban & 51 & $60.0 \%$ & 688 & $54.6 \%$ & \multirow{2}{*}{1.247} & \multirow{2}{*}{0.797} & \multirow{2}{*}{1.952} & \multirow{2}{*}{0.333} \\
\hline & Rural & 34 & $40.0 \%$ & 572 & $45.4 \%$ & & & & \\
\hline \multirow{2}{*}{ Conduct Problem } & Yes & 23 & $27.1 \%$ & 22 & $1.7 \%$ & \multirow{2}{*}{20.875} & \multirow{2}{*}{11.032} & \multirow{2}{*}{39.500} & \multirow{2}{*}{$<0.001$} \\
\hline & No & 62 & $72.9 \%$ & 1238 & $98.3 \%$ & & & & \\
\hline \multirow{2}{*}{$\begin{array}{l}\text { Family history of } \\
\text { ADHD }\end{array}$} & Yes & 19 & $25.0 \%$ & 8 & $1.1 \%$ & \multirow{2}{*}{30.833} & \multirow{2}{*}{12.932} & \multirow{2}{*}{73.514} & \multirow{2}{*}{$<0.001$} \\
\hline & No & 57 & $75.0 \%$ & 740 & $98.9 \%$ & & & & \\
\hline Socioeconomic level & Low/middle & 19 & $25.0 \%$ & 8 & $1.1 \%$ & 7353 & 1781 & 30348 & 0001 \\
\hline socioeconomic rever & High & 57 & $75.0 \%$ & 740 & $98.9 \%$ & 1.535 & 1.181 & 30.348 & 0.001 \\
\hline 'Father occunation & Emoloyed & 70 & $92.1 \%$ & 682 & $91.2 \%$ & 1129 & 472 & 2608 & 0785 \\
\hline Fatner occupation & Unemployed & 6 & $7.9 \%$ & 66 & $8.8 \%$ & 1.129 & $.4 / 2$ & 2.098 & 0.185 \\
\hline Mother & Emoloyed & 21 & $27.6 \%$ & 159 & $21.3 \%$ & 1414 & 831 & 2400 & 0200 \\
\hline occupation & Unemployed & 55 & $72.4 \%$ & 589 & $78.7 \%$ & 1.414 & .831 & 2.409 & 0.200 \\
\hline & Yes & 41 & $53.9 \%$ & 179 & $23.9 \%$ & & & & \\
\hline Consanguinity & No & 35 & $46.1 \%$ & 569 & $76.1 \%$ & 3.724 & 2.301 & 6.026 & $<0.001$ \\
\hline HTN of nreonancy & Yes & 19 & $25.0 \%$ & 11 & $1.5 \%$ & 22333 & 10136 & 40206 & $<0001$ \\
\hline HIN of pregnancy & No & 57 & $75.0 \%$ & 737 & $98.5 \%$ & 22.353 & 10.156 & 49.200 & $<0.001$ \\
\hline Drug intake in & Yes & 27 & $35.5 \%$ & 38 & $5.1 \%$ & 10295 & 5811 & 18241 & $<0001$ \\
\hline pregnancy & No & 49 & $64.5 \%$ & 710 & $94.9 \%$ & 10.295 & 5.811 & 18.241 & $<0.001$ \\
\hline Mother smoking in & Yes & 3 & $3.9 \%$ & 6 & $0.8 \%$ & & & & \\
\hline pregnancy & No & 73 & $96.1 \%$ & 742 & $99.2 \%$ & 5.082 & 1.245 & 20.746 & 0.012 \\
\hline Passive smoking in & Yes & 46 & $60.5 \%$ & 56 & $7.5 \%$ & & & & \\
\hline pregnancy & No & 30 & $39.5 \%$ & 692 & $92.5 \%$ & 18.948 & 11.102 & 32.336 & $<0.001$ \\
\hline Mode of dolivery & NVD & 38 & $50.0 \%$ & 495 & $66.2 \%$ & 511 & 318 & 821 & 0005 \\
\hline Mode of delivery & CS & 38 & $50.0 \%$ & 253 & $33.8 \%$ & .511 & .318 & .821 & 0.005 \\
\hline Birth weioht & Normal & 67 & $88.2 \%$ & 689 & $92.1 \%$ & 637 & 303 & 1343 & 0223 \\
\hline & LBW & 9 & $11.8 \%$ & 59 & $7.9 \%$ & .631 & .303 & 1.343 & 0.223 \\
\hline Prematurity & Yes & 6 & $7.9 \%$ & 46 & $6.1 \%$ & 1308 & 540 & 3171 & 0551 \\
\hline Prematurity & No & 70 & $92.1 \%$ & 702 & $93.9 \%$ & & & & 0.551 \\
\hline Cvanosic & Yes & 7 & $9.2 \%$ & 27 & $3.6 \%$ & & 138 & 8 & \\
\hline Cyanosis & No & 69 & $90.8 \%$ & 721 & $96.4 \%$ & 2.109 & 1.138 & 48 & 0.019 \\
\hline Watching TV & Yes & 48 & $63.2 \%$ & 336 & $44.9 \%$ & 2102 & 1291 & 3,424 & 0002 \\
\hline watcning is & No & 28 & $36.8 \%$ & 412 & $55.1 \%$ & 2.102 & 1.291 & 3.424 & 0.002 \\
\hline Head trauma & Yes & 27 & $35.5 \%$ & 221 & $29.5 \%$ & 1314 & 801 & 2156 & 0270 \\
\hline & No & 49 & $64.5 \%$ & 527 & $70.5 \%$ & 1.314 & .801 & & 0.219 \\
\hline
\end{tabular}

$\mathrm{p} \leq 0.05$ is considered statistically significant, $\mathrm{p} \leq 0.01$ is considered high statistically significant, -comparison between groups done by Chi- Square test

\section{Discussion}

This cross-sectional study was carried out by 1345 pre-school students in the AlQalyubiya governorate. Our results demonstrate that the sociodemographic characteristics of the people studied are dispersed. The age varied between 2.11-5.9 with median children \pm SD aged $4.96 \pm 0.77$ and median children aged 4.9. The most common age was 4.0 $<6.0$ (pre-school age) (84.5 percent ). 610 children were boys $(45.5 \%)$, and 735 boys $(54.6 \%)$ had a 0.83:1.646 (48\%) ratio, of which KG2.739 (45.9\%) were urban children. Most of the youth went to state school.
Elsaid [4] had an average age of 5.46 \pm 0.66 and $4.95 \pm 0.73$ of ADHD children, respectively, above the control group. ADHD was higher in males (69.8 percent) and the males to females ratio was 2.31:1.

Mohamed \& Mohamed [5] noted that the distribution of gender was 2.7:1.

The prevalence of ADHD was 6.3 percent in our study. Of them, $45(3.3 \%)$ had ADHD-combined subtype, $26 \quad(1.9 \%)$ had ADHDhyperactive/impulsive subtype and $14(1.0 \%)$ had ADHD-intense subtype. On the other hand, it was found that $45(3.3 \%)$ had a behaviour problem. 
In Elsaid[4], 9.30 per cent of pre-school children exhibited hyperactivity problems in their attention deficit.

The ADHD rate in pre- and primary school children was $6.5 \%$ in Mohamed et al.[6]

In our study, $53 \%$ of positive children with ADHD had a mixed subtype, $31 \%$ had the undertype of hyperactive/impulsive and $16 \%$ had the undertype.

Elsaid[4] was the most common kind in 26 cases (49.1\%), followed by hyperactive pulses (28.3 percent )

Mohamed \& Mohamed [5] found that $47.4 \%$ of young people with ADHD mostly had ADHD-C, whereas $29.6 \%$ had AdHD-HI and 23\% had ADHDI.

With regard to the socio-demographical characteristics of the children's family, 27 (3.3\%) children had an ADHD family history. The second kid in the sequence of their birth was 396 (48.1 percent).

The risk of ADHD was two times higher in large families than in small households[4] in Elsaid $(\mathrm{OR}=2.33 \mathrm{C}$ 995 percent $=1.07-5.10)$.

Jenahi et al.[7] showed that symptoms of ADHD are linked with high family dimensions. This may explain why childcare is most common if the family is smaller

456 (55.3 percent) of father's education were secondary education. The bulk of Father's (91.3 percent) were employed. As far as mother education is concerned, $484(58.7 \%)$ of mothers have high schools. Most mothers (78.2\%) were unemployed.

The working mother in Elsaid [4] had a twicehigher risk of $\mathrm{ADHD}(\mathrm{OR}=2,79$ percent $\mathrm{CI} 95=2,26$ $6,21)$.

Farahat et al.[8] have shown that housewives and basic employees are more protected than women with high-employment ADHD mothers.

$64.3 \%$ of families had a socio-economic midlevel. The inbreeding of 220 parents (26.7 percent) was positive. The majority of children (79\%) lived with both parents.

Elsaid[4] noted that competent and professional moms' employment raised their ADHD risk by approximately two times $(\mathrm{OR}=2.79$ CI 95 percent=1.26-6.21). At low and middle socioeconomic levels the risk of ADHD has been found to increase by about two times $(\mathrm{OR}=2.49$ $\mathrm{CI} 95 \%=1.10-5.62)$. ADHD risk factors were assessed as big families living with one parent, consanguine parents, father smoking, and family history of chronic disease and the history of ADHD

The increased risk of mental problems for children of a lower socioeconomic class may be explained by the fact that certain factors, such as difficult pregnancy, malnutrition and exposure to environmental toxins, are present.
In $60(7.3 \%)$, parents reprimand their children with harsh words in $66(8 \%)$ cases and insulting events in 47 cases (57 percent).

In 633 (76.8 percent) homes the connection between parents was outstanding; in 692 ( 84 percent) families, the link between parents and children was good.

Regarding the clinical data of children and their mothers. During pregnancy 30 (3.6\%) females were diagnosed with hypertension, while medication was diagnosed at $65(7.9 \%)$. During pregnancy, 9 women $(1.1 \%)$ were smoking and $102(12.4 \%)$ mothers were exposed to passive smoking.

In terms of delivery, $533(64.7 \%)$ women delivered via normal vaginal birth. Low birth weight was identified in 68 ( 8.3 percent) cases and preterm birth weight was recorded in 52 (6.3 percent) cases. In $34(4.1 \%)$ cases, cyanosis was observed.

The average mother age at delivery was 25.10 \pm 2.97 . Most youngsters (64.8 percent) have breast feeding in terms of feeding. Thirty-eight $(46.6 \%)$ young people watched television. 248 youngsters (30.1 percent) sustained head injuries.

As ADHD-C and ADHD-HI subtypes in children, the connection between ADHD subtypes and gender has been considerably enhanced compared to girls and ADHD-I in women as compared to boys.

As far as ADHD-related problems in youngsters are concerned. During the ADHD bivariate analysis, it was revealed that ADHD risk variables related to sex, ADHD family history, socioeconomic level, consanguinity, HTN pregnancy, pregnancy, mother smoking, active mothers and mothers, methods of delivery, cyanosis and TV $(\mathrm{p}<0,05)$

A major risk factor in Elsaid was positive consanguinity[4] that increased ADHD risk by about five times $(\mathrm{OR}=5.93$ percent $=1.23-28.5$ percent $)$.

This corresponds[9] to which the symptoms of ADHD are linked with the consanguine parents.

Elsaid smoking father indicated an increase in danger of about twice $(\mathrm{OR}=2.35$ percent $\mathrm{CI} 95=$ 1.07-5.15)

Elsaid findings[4] showed that first grade children with a related chronic illness are more likely than children with first grade relative chronic diseases to have ADHD (OR $=5.78$ CI95\% = 1.7918.6). Children with first grade relatives with ADHD have increased their chances of developing ADHD to about three times greater than those with ADHD to the first grade linked $(\mathrm{OR}=3.45 \mathrm{CI} 95$ percent $=1.14$, 10.4). Furthermore, behavioural difficulties are associated with ADHD.

\section{Conclusion}

The fact that ADHD is a prevalent condition in children 2-6 years old is a significant issue. Early identification and parenting should be established to improve parental abilities in behavioural management. 


\section{References}

[1] V. Schuch, D. A. Utsumi, T. V. M. M. Costa, L. D. Kulikowski, and M. Muszkat, "Attention Deficit Hyperactivity Disorder in the Light of the Epigenetic Paradigm," Front. Psychiatry.vol.6,pp. 34-45, 2015.

[2] K. Hodgson, A. D. Hutchinson, and L. Denson, "Nonpharmacological Treatments for ADHD," J. Atten. Disord.vol.18,pp. 275-282, May 2014.

[3] D. Daley et al., "Behavioral Interventions in Attention-Deficit/Hyperactivity Disorder: A Meta-Analysis of Randomized Controlled Trials Across Multiple Outcome Domains," J. Am. Acad. Child Adolesc. Psychiatry.vol. 53, pp. 835-847.e5, 2014.

[4] N. B.Elsaid, "Prevalence of Attention Deficit Hyperactivity Disorder among Preschool Children (3-6 Years), Menoufia Governorate," Egypt. Fam. Med. J.vol. 2, pp. 1-15, 2018.

[5] E. Mohamed and E. Mohamed, "Prevalence of Attention-Deficit/Hyperactivity Disorder Among A Sample of Primary School Children in Al- Qalyubia Governorate.vol. 2, pp. 2-12, 2015.

[6] A. H. Mohammed, H. A. A. Gawad, and M. M. M. Ahmed, "Gross motor development in Egyptian preschool children with attention deficit hyperactivity disorder: Pilot study," J. Adv. Pharm. Educ. Res.vol. 7,pp. 438-442, 2017.

[7] E. Jenahi, M. S. Khalil, and H. Bella, "Prevalence of attention deficit hyperactivity symptoms in female schoolchildren in Saudi Arabia," Ann. Saudi Med.vol.32,pp. 462-468, 2012.

[8] T. Farahat, M. Alkot, A. Rajab, and R. Anbar, "Attention-deficit hyperactive disorder among primary school children in Menoufia Governorate, Egypt," Int. J. Family Med.vol. 2014,pp. 77-89, 2014.

[9] A. Bener, R. Al Qahtani, and I. Abdelaal, "The Prevalence of ADHD Among Primary School Children in an Arabian Society," J. Atten. Disord., vol.10,pp. 77-82, 2006. 